440

\title{
ÁCIDO 2,3,5-TRI-IODOBENZOICO (TIBA) NA MICROPROPAGAÇÃO DE ABACAXIZEIRO 'IAC GOMO-DE-MEL' ${ }^{1}$
}

\author{
SÉRGIO MARQUES COSTA ${ }^{2}$, CHRYSTIANE BORGES FRÁGUAS 3 , \\ DÉBORA ZANONI DO PRADO ${ }^{4}$, GIUSEPPINA PACE PEREIRA LIMA ${ }^{5}$
}

RESUMO -O abacaxi 'IAC Gomo-de-Mel' é uma espécie economicamente importante devido a diversas características sensoriais. Uma das técnicas para obter maior número de plantas é a micropropagação. Assim, o objetivo deste trabalho foi avaliar a ação do TIBA (ácido 2,3,5-tri-iodobenzoico) na formação de brotos e raízes do abacaxizeiro 'IAC Gomo-de-Mel', assim como possíveis alterações na morfologia de tecidos foliares. Foram utilizados segmentos das gemas da coroa de abacaxi, com aproximadamente $1 \mathrm{~cm}$, oriundos de cultivo em meio líquido, suplementadas com $1,0 \mathrm{mg} \mathrm{L}^{-1} \mathrm{BAP}+0,5 \mathrm{mg} \mathrm{L}^{-1} \mathrm{NAA}$, sendo posteriormente inoculados em meio MS líquido contendo diversas concentrações de TIBA, em condição de luz e temperatura controladas, implantando 3 diferentes experimentos para as análises biométrica, bioquímica e anatômica. Os experimentos foram implantados em delineamento experimental inteiramente ao acaso, com 8 tratamentos, com 4 repetições para as análises biométricas e 5 repetições para a bioquímica e anatômica. Ao final de 60 dias, foram avaliados o número e o comprimento das brotações, o comprimento da planta-mãe e o número de raízes. A análise da atividade de AIA-oxidase foi realizada no dia da instalação do experimento e aos 15; 30; 45 e 60 dias de cultivo. Conclui-se que o TIBA isoladamente não induz brotações. A redução na atividade da AIA-oxidase foi relacionada com a emissão de novas raízes, e o aumento na espessura dos tecidos foliares ocorreu após aplicação exógena de TIBA, em abacaxizeiro in vitro.

Termos para indexação: abacaxi-de-gomo, AIA-oxidase, micropropagação, anatomia vegetal.

Abreviações: TIBA - ácido 2,3,5-tri-iodobenzoico; BAP - benzilaminopurina; NAA- ácido naftalenoacético; AIA - ácido indolacético.

\section{TIBA IN VITRO MULTIPLICATION OF PINEAPPLE 'IAC GOMO-DE-MEL}

\begin{abstract}
The cultivar 'IAC Gomo-de-Mel' is an economically important species due to different sensory characteristics. One of the techniques to obtain higher number of plants is micropropagation. Thus, the aim of this study was to evaluate the effects of TIBA (2,3,5 - triiodobenzoic acid) in the formation of shoots and roots of pineapple 'IAC Gomo-de-Mel ', as well as possible changes in the morphology of leaf tissues. It were used segments of the gems in the crown of pineapple, with approximately $1 \mathrm{~cm}$, arising from cultivation in liquid medium supplemented with $1.0 \mathrm{mg} \mathrm{L}^{-1} \mathrm{BAP}+0.5 \mathrm{mg} \mathrm{L}^{-1} \mathrm{NAA}$, and subsequently inoculated in MS liquid containing various concentrations of TIBA in light condition and controlled temperature, deploying three different experiments for biometric, biochemical and anatomical analyzes. The experiments were implanted in a completely randomized experimental design with 8 treatments and 4 replicates for biometric analysis and 5 replicates for biochemical and anatomical analysis. At the end of 60 days, were evaluated the number and length of shoots, length of the mother plant and the number of roots. The analysis of the activity of IAA-oxidase was performed on the day of the experiment and at 15, 30, 45 and 60 days of cultive. We conclude that the TIBA alone does not induce shoots formation. The reduction in the IAA-oxidase activity was related to the emission of new roots and an increase in leaf thickness occurred after exogenous application of TIBA in pineapple 'Gomo-de-Mel' cultivated in vitro.
\end{abstract}

Index terms: pineapple-of-gomo, IAA oxidase, micropropagation, plant anatomy.

Abbreviations: TIBA - 2,3,5-triiodobenzoic acid; BAP - benzylaminopurine; NAA-Naphthalene acetic acid, IAA - Indole-3-acetic acid.

\footnotetext{
${ }^{1}$ (Trabalho 353-13). Recebido em: 25-09-2013. Aceito para publicação em: 05-02-2014.

${ }^{2}$ Pós-doutorando do Departamento de Química e Bioquímica, Universidade Estadual Paulista, Botucatu-SP. Email: marxcosta@gmail.com ${ }^{3}$ Laboratório de Bioquímica Vegetal, Departamento de Química e Bioquímica, Universidade Estadual Paulista “Júlio de Mesquita Filho", Botucatu-SP. Email: chrysbf@gmail.com

${ }^{4}$ Mestranda do Departamento de Química e Bioquímica, Universidade Estadual Paulista, Botucatu-SP. Email: deborazp@hotmail.com ${ }^{5}$ Professora da Universidade Estadual Paulista, Departamento de Química e Bioquímica, Botucatu-SP. Email: gpplima@ibb.unesp.br
} 


\section{INTRODUÇÃO}

O abacaxi 'IAC Gomo-de-mel' ou abacaxide-gomo, provavelmente resultante de cruzamento natural, produz fruto com $1.044 \mathrm{~g}$ de peso médio, casca de espessura média, polpa de coloração amarelo-ouro suculenta e de ótimo sabor (OLIVEIRA, 2001). É possível produzir in vitro 161.080 plantas de abacaxi após oito meses, partindo de apenas uma planta com oito mudas e dez gemas axilares cada (ALMEIDA et al., 2002). Esta quantidade é suficiente para o cultivo de 2,3 ha em plantio adensado (70.000 plantas/ ha) (SANTANA et al., 2001). Utilizando o método convencional de propagação de abacaxizeiro, levaria sete anos e seis meses para obter 32.700 plantas a partir de uma planta inicial, o que seria suficiente para, aproximadamente, 0,5 ha (MATOS et al., 1988). Esta comparação demonstra a vantagem da micropropagação do abacaxizeiro em relação à propagação convencional.

Algumas substâncias adicionadas ao meio de cultura podem influenciar no crescimento e desenvolvimento dos tecidos ainda na fase de cultivo in vitro por atuarem na regulação do metabolismo, como o ácido o indolacético (AIA), um ácido fraco, que é sintetizado em regiões meristemáticas do ápice da parte aérea e transportado à raiz. Então, é redirecionado para a região cortical e tecidos epidérmicos para gerar um gradiente basípeto de auxina (BLAKESLEE et al., 2005).

O transporte polar da auxina fornece informações essenciais de direcionamento e posicionamento para processos de desenvolvimento, como diferenciação vascular, dominância apical, desenvolvimento de órgãos e tropismo (BLILOU et al., 2005). Por outro lado, a inativação do AIA é mediada via reações foto-oxidativas e sistemas oxidativos enzimáticos (SALISBURY; ROSS, 1994). Atribui-se ao sistema oxidativo enzimático, conhecido por AIA-oxidase, um dos papéis de importância maior no controle dos níveis endógenos de AIA nas plantas. Alguns estudos demonstram que o declínio da atividade de AIA-oxidase coincide com a diminuição no teor de AIA, devido à formação de conjugados com AIA, sendo que esses conjugados podem reter ou perder a atividade auxínica (HRUBCOVÁA et al., 2000).

Para maior esclarecimento do papel da auxina no controle do crescimento de gemas laterais, diversos estudos sobre os efeitos de substâncias inibidoras do transporte de auxina, como, por exemplo, o TIBA (ácido 2,3,5-tri-iodobenzoico). Foi demonstrado que o TIBA induz a formação de brotos, aumentando a taxa proliferativa de algumas espécies, como Rosa hybrida (rosa) (SINGH;SYAMAL, 2000). Por outro lado, outros estudos não verificaram respostas para a indução de gemas com a utilização de TIBA (KUMAR et al., 2005).

O objetivo deste trabalho foi avaliar se o TIBA pode agir como indutor da formação de brotos e raízes para aumentar a taxa de multiplicação em abacaxizeiro cv 'IAC Gomo-de-Mel', assim como possíveis alterações na morfologia de tecidos foliares.

\section{MATERIAL E MÉTODOS}

O experimento foi conduzido no Departamento de Química e Bioquímica, do Instituto de Biociências, Universidade Estadual Paulista, Câmpus de Botucatu, Botucatu, São Paulo. Segmentos de plantas oriundas das gemas da coroa de abacaxi (Ananas comosus L. cv IAC Gomo-de-Mel), com aproximadamente $1 \mathrm{~cm}$, oriundas do cultivo em meio líquido suplementado com 1,0 mg L $\mathrm{m}^{-1} \mathrm{BAP}$ (6-benzil aminopurina) + $0,5 \mathrm{mg}$ $\mathrm{L}^{-1} \mathrm{ANA}$ (ácido naftaleno acético) (FRÁGUAS et al., 2009), com 60 dias (obtidas de dois subcultivos, com intervalo de 20 dias), foram inoculados em meio MS (MURASHIGE; SKOOG, 1962) líquido, em frascos com capacidade para $200 \mathrm{~mL}$, de acordo com os tratamentos $\left(\mathrm{T} 1=\mathrm{MS} ; \mathrm{T} 2=\mathrm{MS}+1,0 \mathrm{mg} \mathrm{L}^{-1} \mathrm{BAP}\right.$ $+0,5 \mathrm{mg} \mathrm{L}^{-1} \mathrm{NAA} ; \mathrm{T} 3=\mathrm{MS}+0,5 \mu \mathrm{M}$ TIBA; $44=$ $1,0 \mu \mathrm{M}$ TIBA; T5 = MS $+2,0 \mu \mathrm{M}$ TIBA; T6 $=\mathrm{MS}$ $+4,0 \mu \mathrm{M}$ TIBA; $\mathrm{T} 7=\mathrm{MS}+8,0 \mu \mathrm{M}$ TIBA, e $\mathrm{T} 8=$ $\mathrm{MS}+16,0 \mu \mathrm{M}$ TIBA). Todos os meios continham $30 \mathrm{~g} \mathrm{~L}^{-1}$ de sacarose. Foi ajustado o $\mathrm{pH}$ para 5.8. Os meios foram autoclavados a $120^{\circ} \mathrm{C}$ por 20 minutos. Após inoculação dos segmentos das plantas, os frascos foram vedados com parafilm, e o material vegetal foi mantido em sala com temperatura de 27 $\pm 1^{\circ} \mathrm{C}$, irradiância de $35 \mu \mathrm{mol} \mathrm{m}{ }^{-2} \mathrm{~s}^{-1}$ e fotoperíodo de 16 horas luz.

Após 60 dias, foram avaliados o número e o comprimento das brotações, comprimento da planta-mãe (explante inicialmente inoculado no meio de cultura a partir do qual se formaram as novas brotações) e o número de raízes. A análise bioquímica da atividade da AIA-oxidase (HUANG et al., 1997) foi realizada no dia da instalação do experimento e aos $15 ; 30 ; 45$ e 60 dias de cultivo.

No final do cultivo, foram coletadas plantas de cada tratamento para realização de cortes foliares para estudo da influência do TIBA na anatomia foliar. Folhas completamente expandidas cultivadas in vitro foram coletadas nos diferentes tratamentos. As folhas foram fixadas em FAA 50 (JOHANSEN, 1940) e conservadas em etanol a 70\% (JENSEN, 1962). Para a confecção do laminário permanente, as amostras foram desidratadas em série etílica; infiltradas 
e incluídas em hidroxil-etil-metacrilato Leica (GERLACH, 1969), seccionadas em micrótomo rotativo, coradas com azul de toluidina (O'BRIEN et al., 1964) e montadas em resina sintética. Os resultados foram ilustrados por meio de micrografias obtidas em fotomicroscópio.

A análise dos tecidos foliares da região mediana foi efetuada com auxílio de ocular micrométrica. Para as avaliações relativas à caracterização dos estômatos (número médio por $\mathrm{mm}^{2}$ ), cortes paradérmicos foram realizados na região mediana das folhas e colocados sobre uma lâmina contendo safranina a $1 \%$, e montados em gelatina glicerinada.

O delineamento experimental utilizado foi o inteiramente ao acaso, com quatro repetições e dez plântulas por parcela. Para as análises bioquímicas, utilizou-se de cinco repetições com uma planta por parcela e para o estudo anatômico, cinco repetições com três medições por parcela. A análise estatística foi realizada pelo programa Sisvar (FERREIRA, 2000), por meio do teste de médias Scott-Knott e regressão polinomial.

\section{RESULTADOS E DISCUSSÃO}

No período de cultivo in vitro do abacaxizeiro 'IAC Gomo-de-mel', em meios de cultura na presença de diferentes concentrações de TIBA, uma semana após a inoculação dos explantes, ocorreu emissão de novas folhas e, aos 30 dias de cultivo, novas brotações e raízes estavam formadas (Figura 1). As plantas em meio contendo 16,0 $\mu \mathrm{M}$ TIBA(T8) não se desenvolveram bem, apresentando oxidação e morte após a primeira semana de cultivo.

Aos 60 dias, maior número de brotações $(3,98)$ ocorreu no tratamento usando 1,0 BAP $+0,5$ ANA (T2), porém as plântulas apresentavam aspecto hiper-hídrico (aparência vítrea, folhas túrgidas e endurecidas) e tamanho reduzido (Figuras 1 e 2A). Embora com grande eficiência em promover a formação de brotações adventícias para muitas espécies, o BAP tem proporcionado alterações morfológicas, principalmente quando utilizado em altas concentrações (LAI et al., 2005) e, nesse estudo, provavelmente, mesmo tendo sido a concentração ideal para a indução do maior número de brotações, a concentração usada pode ter influenciado na formação de células hiper-hídricas. A hiper-hidricidade é um problema grave para diversas espécies cultivadas in vitro, em meio líquido ou semissólido quando o meio é enriquecido por citocininas (PIATCZAK et al., 2005). Apesar de a utilização de citocinina ser essencial à multiplicação da parte aérea, seu excesso é tóxico e caracteriza-se, principalmente, por excessivo número de brotos, redução no tamanho das folhas, encurtamento dos entrenós, engrossamento exagerado dos caules e hiper-hidricidade (LESHEM et al., 1988), como observado neste estudo. A hiperhidricidade em Gomo-de-Mel ocorreu apenas no tratamento contendo BAP e ANA, ou seja, a presença de TIBA não influenciou na formação de brotações com hiper-hidricidade, embora já tenha sido relatada a influência de TIBA ( $\left.1 \mathrm{mg} \mathrm{L}^{-1}\right)$, induzindo hiperhidricidade na formação de brotos de Beta vulgaris (beterraba) (TOLDI et al., 1996).

A suplementação do meio MS com TIBA isoladamente não aumentou o número de brotações (Figura 2A), sugerindo que pode não ter havido a inibição do transporte polar de auxina e, consequentemente, não ocorreu alteração no balanço auxina/citocinina. A inibição por TIBA no número de brotos e raízes formados também foi relatada por Kumar et al. (2005). Por outro lado, algumas vezes, pode agir como indutor da taxa de proliferação de brotos em rosas (SINGH; SYAMAL, 2000).

Ocorreu diminuição do comprimento dos brotos (Figura 2B) nas maiores concentrações de TIBA aplicado exogenamente, isto é, a partir de $1,0 \mu \mathrm{mol}$ de TIBA. O maior comprimento das brotações $(2,01 \mathrm{~cm})$ foi verificado em meio sem regulador, o que poderia ser atribuído ao pequeno número de brotações formadas, permitindo melhor crescimento e desenvolvimento das plantas. Sob efeito de 0,5 $\mu \mathrm{mol}$ de TIBA (T3), observou-se 1,51 $\mathrm{cm}$ de comprimento para as brotações, diferindo estatisticamente do tratamento sem reguladores. Os demais tratamentos não apresentaram diferença estatística entre si, isto é, os valores não ultrapassaram 1,32 cm de comprimento (Figura 2B). Embora não diferindo estatisticamente, as brotações em meio contendo $16 \mu$ moles de TIBA não ultrapassaram $0,62 \mathrm{~cm}$ de comprimento, e as folhas apresentavam aspecto de murcha, além da maioria dos explantes inoculados terem morrido após uma semana de cultivo (Figura 1). Possivelmente, a concentração utilizada do TIBA (16 $\mu$ moles) foi fitotóxica para esta espécie, inibindo o desenvolvimento das plântulas e de novas brotações.

Os comprimentos das microplantas (Figura 2C) inicialmente inoculadas ao meio de cultura (plantas-mãe) foram semelhantes, diferindo apenas do tratamento usando BAP + ANA e na maior concentração de TIBA (16,0 $\mu$ moles), que apresentaram os menores comprimentos: 3,49 e $3,3 \mathrm{~cm}$, respectivamente. Uma hipótese para os resultados pode ter sido as grandes concentrações usadas, o que nos leva a sugerir estudos futuros com 
essa cultivar em concentrações mais baixas de TIBA.

A maior concentração de TIBA pode também ter sido fitotóxica para as raízes (Figura 2D). Por outro lado, concentrações entre 0,5 e 1,0 $\mu \mathrm{mol}$ de TIBA não mostraram diferença do meio ausente de reguladores. Esse efeito observado pode ser relacionado ao balanço hormonal endógeno favorável à auxina, comprovando que não houve efeito do TIBA na inibição da translocação do AIA. No tratamento usando apenas BAP e ANA (T2), não houve formação de raízes, devido, provavelmente, ao balanço favorável à citocinina conferido pela utilização de $1,0 \mathrm{mg} \mathrm{L}^{-1}$ de BAP.

$A$ atividade de AIA-oxidase foi inicialmente de $0,0034 \mu \mathrm{mol}$ AIA g $\mathrm{mf}^{-1} \min ^{-1}$ (Figura 3), ocorrendo pequenas variações entre os tratamentos. Todos os materiais de abacaxi analisados, sob efeito dos tratamentos, apresentaram respostas semelhantes em relação à atividade da AIA-oxidase. Até o $15^{\circ}$ dia, verificou-se aumento da atividade da AIA-oxidase, sugerindo uma possível inibição no transporte de AIA até este período de cultivo, e, logo após, há uma diminuição. Já foi demonstrado que o declínio da atividade de AIA-oxidase coincide com a diminuição no teor de AIA, devido, provavelmente, à formação de conjugados com AIA (HRUBCOVÁA et al., 2000). O AIA pode ligar-se a outras moléculas na planta, produzindo conjugados que podem reter ou perder a atividade auxínica (SALISBURY; ROSS, 1994).

Sob tratamento em maior concentração de TIBA, ocorreram as maiores atividades de AIAoxidase até os 30 dias, sendo que após este período as plantas já estavam com perda de turgescência dos tecidos, com baixo desenvolvimento (Figura 1), e, possivelmente, os resultados posteriores sejam influência do estado fisiológico do vegetal. Em geral, a formação de raízes coincidiu com a redução da atividade da AIA-oxidase aos 30 dias (Figuras 1 e 3), indicando que a redução da atividade da AIA-oxidase acompanha a formação de raízes adventícias. A redução da atividade e o aumento da concentração endógena de auxinas indicam que a auxina é necessária para o processo de enraizamento (LIU et al., 1996).

Em abacaxizeiro 'IAC Gomo-de-Mel' micropropagado, como na maioria das bromeliáceas, foi observado que a lâmina foliar apresenta nas faces adaxial e abaxial epiderme uniestratificadas, hipoestomática do tipo tetracítico, tricomas tectores em ambas as faces, mesofilo homogêneo, com parênquima aquífero voltado para a face adaxial, e o parênquima clorofiliano, voltado para a face abaxial. Inúmeros idioblastos contendo ráfides aparecem no mesofilo (Figura 4).

As espessuras da epiderme adaxial e abaxial variaram de acordo com a aplicação dos reguladores (Tabela 1). Em todos os tratamentos, ocorreu a presença de tricomas tectores por toda a expansão da epiderme, em ambas as faces. A maior espessura da epiderme adaxial ocorreu no tratamento sem reguladores (T1), onde, provavelmente, sua ausência possibilitou melhor desenvolvimento deste tecido. Por outro lado, a epiderme abaxial, neste tratamento, apresentou os menores valores, diferindo apenas do uso de BAP e ANA e do tratamento com maior concentração de TIBA. Outro fator que pode ter contribuído para esse efeito é a hiper-hidricidade, que pode ter alterado o desenvolvimento das células da epiderme, resultando em menor espessura da epiderme, adaxial no tratamento contendo BAP/ ANA e no tratamento contendo maior concentração de TIBA, embora não tenha sido observada hiperhidricidade, a concentração utilizada pode ter sido muito alta, refletindo em baixo desenvolvimento da epiderme adaxial. Nesse tratamento, as plantas não apresentaram bom desenvolvimento, ocorrendo a morte após oxidação intensa dos tecidos, logo após a primeira semana de cultivo.

Analisando-se os tecidos do parênquima aquífero e clorofiliano, foi observado que a presença de TIBA, independentemente da concentração, induziu aumento da espessura destes tecidos, quando comparados com os tratamentos onde não foi usada a substância (Tabela 1 e Figura 4). Foi constatada maior espessura $(297,50 \mu \mathrm{m})$ do parênquima aquífero em plantas cultivadas em meio MS com 8,0 $\mu$ moles de TIBA, seguido pelo tratamento com 1,0 $\mu$ moles de TIBA $(236,98 \mu \mathrm{m})$, com 4 e 5 camadas. As plantas cultivadas apenas no meio MS apresentaram parênquima aquífero com 2 a 3 camadas e grande volume celular, quando comparadas aos outros tratamentos. Por outro lado, a espessura do parênquima clorofiliano deste tratamento não diferiu estatisticamente do tratamento com 0,5 $\mu$ moles TIBA (Figura 4C, D e G). A redução na espessura do parênquima clorofiliano de plantas cultivadas com diferentes reguladores vegetais foi descrita em trabalhos anteriores (TOMA et al., 2004). Por outro lado, inibição da expansão das células do mesofilo e alterações no conteúdo de clorofila de Arabidopsis thaliana, cultivadas na presença de TIBA, foram relatadas (PASTERNAK et al., 2005).

Observou-se, no mesofilo das plantas cultivadas em meio com BAP e ANA, células colapsadas (Figura 4B), possivelmente, devido à hiper-hidricidade das plantas. Em estudos anteriores, o efeito da hiper-hidricidade sob a morfologia do 
mesofilo foi descrita em diversas espécies. Em brotos de girassol hiper-hídricos, ocorreu redução do parênquima paliçádico, aumento do volume celular, hipolignificação do sistema vascular e a hipertrofia dos parênquimas cortical medular (FAUGUEL et al., 2008).

No estudo da epiderme abaxial, maior número de estômatos ocorreu em plantas cultivadas com TIBA, mas não diferiram estatisticamente entre si (Tabela 1). Não houve diferença entre os tratamentos sem reguladores e naquele usando BAP e ANA, e foi observado menor número médio de estômatos por $\mu \mathrm{m}^{2}$. Sun et al. (1995) citam que os estômatos são estruturas fundamentais para as plantas porque, através deles, ocorrem os processos de troca gasosa, e, nesse caso, essas plantas, oriundas desses tratamentos, poderiam ser prejudicadas quanto a sua produção, devido ao menor número de estômatos. Portanto, qualquer variação em número e/ou tamanho pode acarretar maior ou menor eficiência da planta quanto à taxa fotossintética.
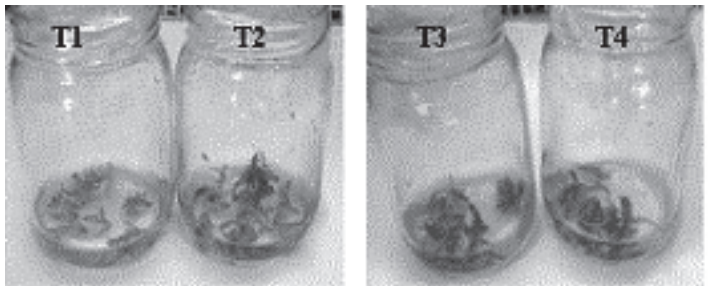

15 dias
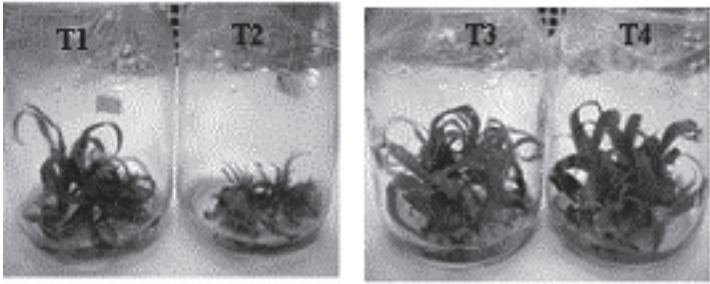

30 dias
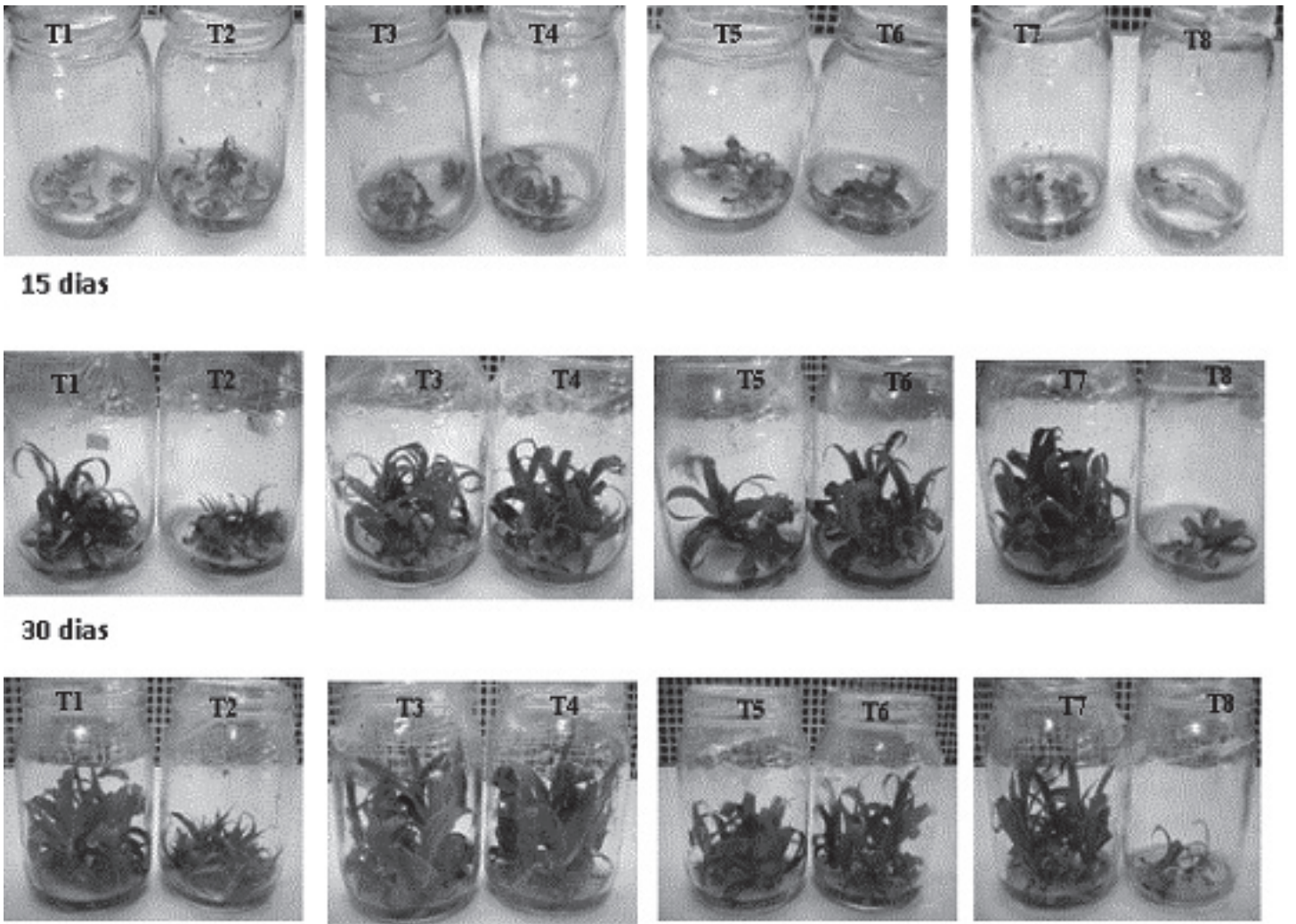

\section{5 dias}
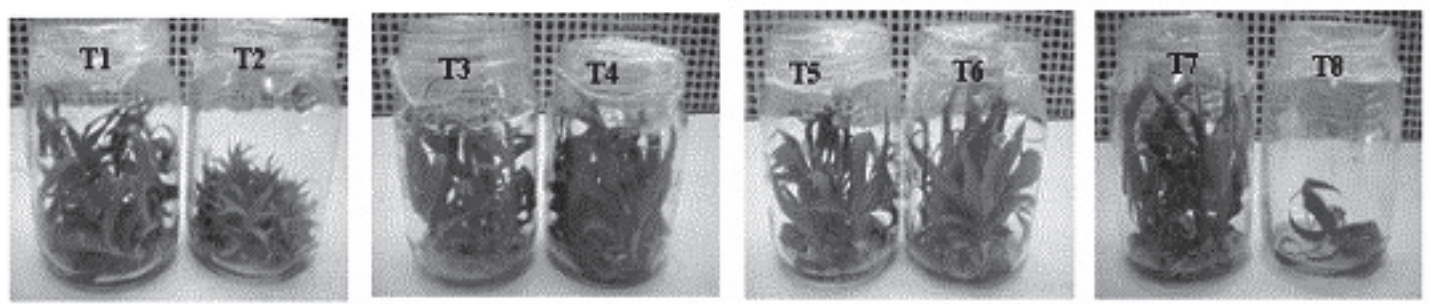

60 dias

FIGURA 1- Microplantas de abacaxizeiro 'IAC Gomo-de-Mel' cultivadas em meio de cultura MS com diferentes concentrações $(\mathrm{T} 1=\mathrm{MS} ; \mathrm{T} 2=\mathrm{MS}+1,0 \mathrm{mg} \mathrm{L}-1 \mathrm{BAP}+0,5 \mathrm{mg} \mathrm{L}-1 \mathrm{NAA} ; \mathrm{T} 3=\mathrm{MS}$ $+0,5 \mathrm{mM}$ TIBA; $\mathrm{T} 4=1,0 \mathrm{mM}$ TIBA; $\mathrm{T} 5=\mathrm{MS}+2,0 \mathrm{mM}$ TIBA; $\mathrm{T} 6=\mathrm{MS}+4,0 \mathrm{mM}$ TIBA; $\mathrm{T} 7=\mathrm{MS}+8,0 \mathrm{mM}$ TIBA, e T8 $=\mathrm{MS}+16,0 \mathrm{mM}$ TIBA) de TIBA, aos 15; 30; 45 e 60 dias. 

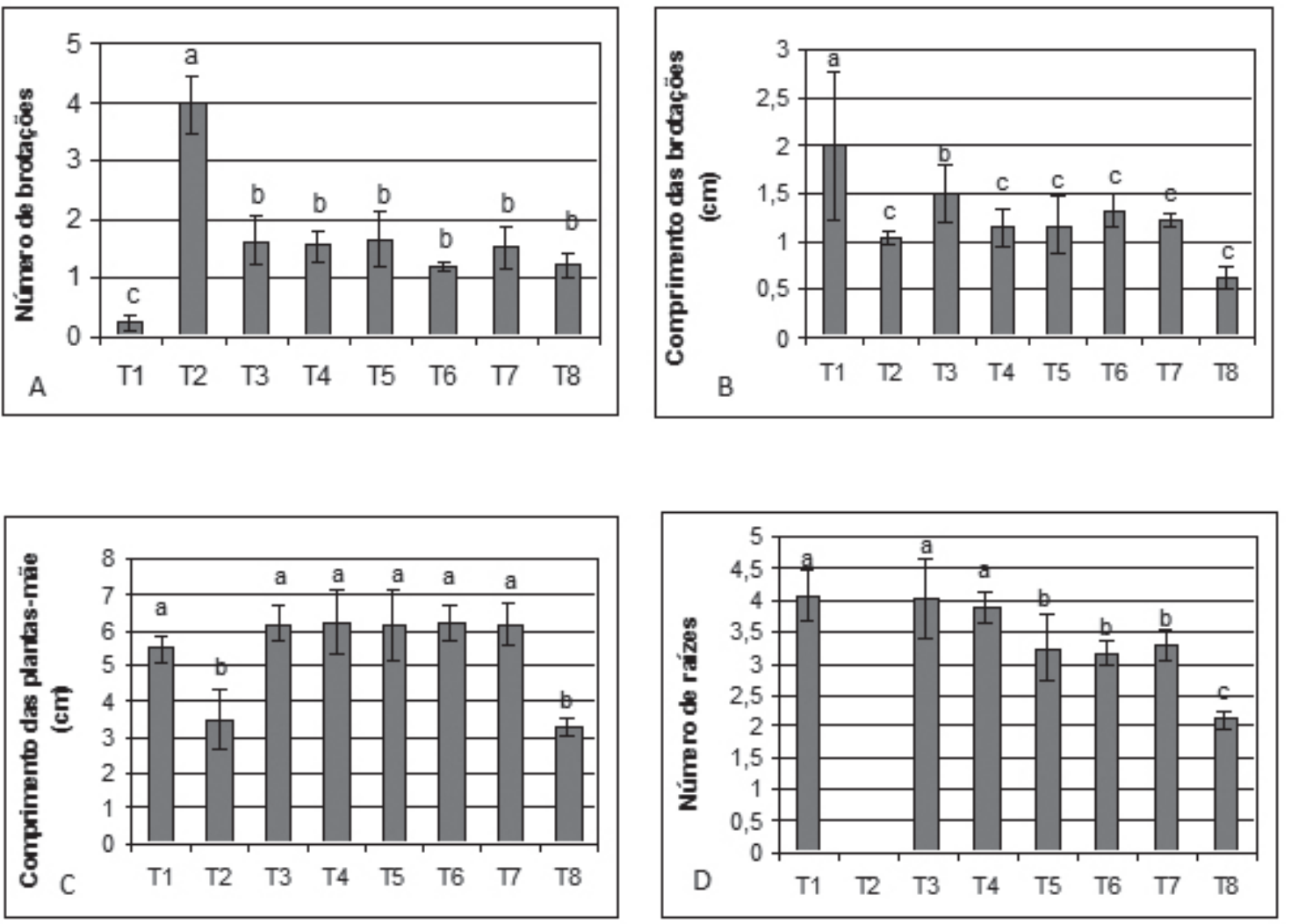

FIGURA 2- Número de brotações (A), comprimento das brotações (B) e das plantas-mãe (C) e número de raízes (D) de abacaxizeiro 'IAC Gomo-de-Mel', aos 60 dias, cultivado em meio de cultura MS com diferentes concentrações de TIBA.

TABELA 1- Espessura média $(\mu \mathrm{m})$ dos tecidos epidérmicos, parênquima aquífero e clorofiliano e número de estômatos $\left(\mu \mathrm{m}^{2}\right)$ em plantas de abacaxizeiro 'IAC Gomo-de-Mel' cultivados em meio de cultura MS com diferentes concentrações de TIBA.

\begin{tabular}{lccccc}
\hline \multicolumn{1}{c}{ Tratamentos } & $\begin{array}{c}\text { Epiderme } \\
\text { adaxial }\end{array}$ & $\begin{array}{c}\text { Parênquima } \\
\text { aquífero }\end{array}$ & $\begin{array}{c}\text { Parênquima } \\
\text { clorofiliano }\end{array}$ & $\begin{array}{c}\text { Epiderme } \\
\text { abaxial }\end{array}$ & $\begin{array}{c}\text { Número de } \\
\text { estômatos }\end{array}$ \\
\hline MS (T1) & $26,902 \mathrm{a}$ & $77,114 \mathrm{f}$ & $177,366 \mathrm{~g}$ & $6,724 \mathrm{c}$ & $2,892 \mathrm{~b}$ \\
$\mathrm{MS}+1,0 \mathrm{BAP}+0,5 \mathrm{NAA}(\mathrm{T2})$ & $10,146 \mathrm{e}$ & $137,352 \mathrm{e}$ & $196,622 \mathrm{f}$ & $10,116 \mathrm{~b}$ & $2,264 \mathrm{~b}$ \\
$\mathrm{MS}+0,5 \mu \mathrm{M}$ TIBA (T3) & $15,868 \mathrm{c}$ & $206,800 \mathrm{c}$ & $176,968 \mathrm{~g}$ & $8,426 \mathrm{c}$ & $4,532 \mathrm{a}$ \\
$\mathrm{MS}+1,0 \mu \mathrm{M}$ TIBA (T4) & $16,840 \mathrm{c}$ & $236,982 \mathrm{~b}$ & $209,740 \mathrm{~d}$ & $7,560 \mathrm{c}$ & $4,330 \mathrm{a}$ \\
$\mathrm{MS}+2,0 \mu \mathrm{M}$ TIBA (T5) & $19,564 \mathrm{~b}$ & $206,002 \mathrm{c}$ & $245,594 \mathrm{c}$ & $7,484 \mathrm{c}$ & $4,930 \mathrm{a}$ \\
$\mathrm{MS}+4,0 \mu \mathrm{M}$ TIBA (T6) & $21,648 \mathrm{~b}$ & $149,420 \mathrm{~d}$ & $272,726 \mathrm{a}$ & $8,364 \mathrm{c}$ & $4,796 \mathrm{a}$ \\
$\mathrm{MS}+8,0 \mu \mathrm{M}$ TIBA (T7) & $20,498 \mathrm{~b}$ & $297,500 \mathrm{a}$ & $253,052 \mathrm{~b}$ & $6,984 \mathrm{c}$ & $4,262 \mathrm{a}$ \\
$\mathrm{MS}+16,0 \mu \mathrm{M}$ TIBA (T8) & $13,286 \mathrm{~d}$ & $206,282 \mathrm{c}$ & $202,576 \mathrm{e}$ & $14,216 \mathrm{a}$ & $3,996 \mathrm{a}$ \\
\hline
\end{tabular}

Médias seguidas da mesma letra (na vertical) não diferem significativamente entre si, pelo teste de Scott-Knott 


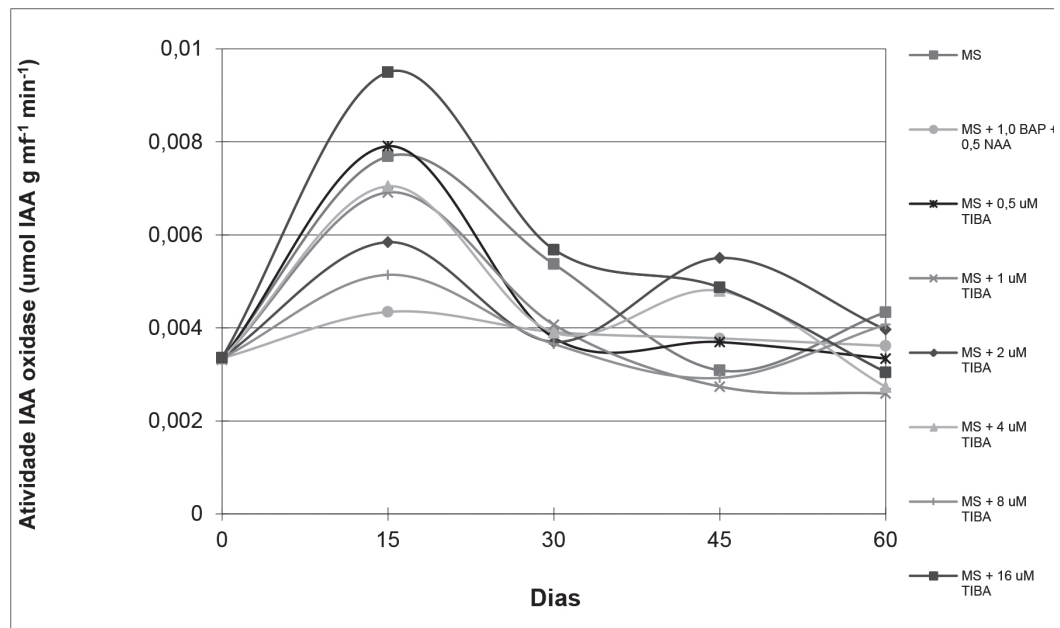

$$
\begin{array}{ll}
\text { T1: } y=0,004420+0,000099 x-0,000002 x^{2} & R^{2}=0,76 \\
\text { T2: } y=0,003525+0,000038 x-0,000001 x^{2} & R^{2}=0,85 \\
\text { T3: } y=0,00444+0,000082 x-0,000002 x^{2} & R^{2}=0,75 \\
\text { T4: } y=0,004233+0,000074 x-0,000002 x^{2} & R^{2}=0,81 \\
\text { T5: } y=0,003714+0,000084 x-0,000001 x^{2} & R^{2}=0,76 \\
\text { T6: } y=0,004011+0,000118 x-0,000002 x^{2} & R^{2}=0,83 \\
\text { T7: } y=0,003913+0,000005 x-0,000001 x^{2} & R^{2}=0,72 \\
\text { T8: } y=0,004494+0,000211 x-0,000004 x^{2} & R^{2}=0,82
\end{array}
$$

FIGURA 3- Atividade de AIA-oxidase ( $\mu \mathrm{mol}$ AIA $\mathrm{g} \mathrm{mf}^{-1} \mathrm{~min}^{-1}$ ) em plântulas de abacaxizeiro 'IAC Gomode-Mel' cultivadas em meio de cultura MS com diferentes concentrações de TIBA, aos 0;15; $30 ; 45$ e 60 dias.

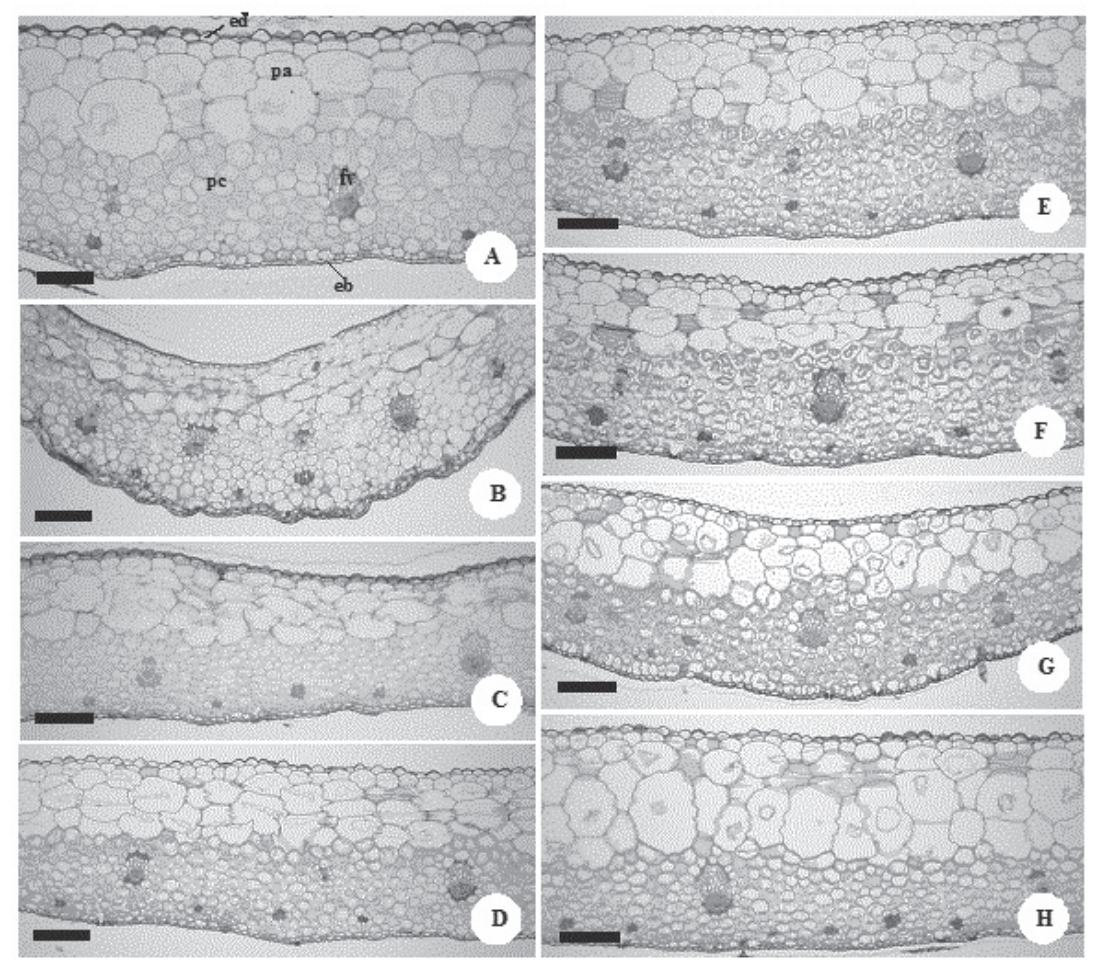

\begin{abstract}
Figmas-A-Corte transversal de follhas de abacaxizeiro 'TACGomo-de-mel'AA T1 -MS_B_T 2 - MS + 1,0 mg L $\mathrm{L}^{1}$ BAP + 0,5 mg $\mathrm{L}^{-1}$ NAA C_ T 3 - MS + 0,5 um TIBA D_T 4 - MS + 1,0 um

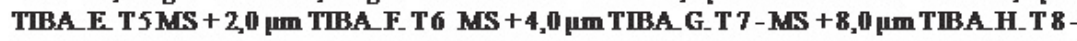
MS + 16,0 um TIBA (eb = face abaxial da cpideme; ed = face adaxial da epideme; fv = feixe vascular,pa $=$ parenquimaaqüifero; pc $=$ parenquimaclorofiliano)_Barra $=150 \mu \mathrm{m}$.
\end{abstract}

FIGURA 4- Anatomia foliar de plântulas de abacaxizeiro 'IAC Gomo-de-Mel' cultivadas em meio de cultura MS com diferentes concentrações de TIBA. 


\section{CONCLUSÕES}

Para aumentar a taxa de multiplicação in vitro, TIBA não induz brotações em abacaxizeiro 'IAC Gomo-de-Mel'. A redução na atividade da AIAoxidase está relacionada com a emissão de novas raízes. $\mathrm{O}$ aumento na espessura dos tecidos foliares pode ser observado com a aplicação exógena TIBA.

\section{REFERÊNCIAS}

ALMEIDA, W.A.B.; SANTANA, G.S.; RODRIGUEZ, A.P.M.; COSTA, M.P.C.C. Optimization of a protocol for the micropropagation of pineapple. Revista Brasileira de Fruticultura, Jaboticabal, v.24, n.2, p. 296-300, 2002.

BLAKESLEE, J.J.; PEER, W.A.; MURPHY, A.S. Auxin transport. - Current Opinion in Plant Biology, Stuttgart, v. 8, p. 494-500, 2005.

BLILOU, I.; XU, J.; WILDWATER, M.; WILLEMSEN, V.; PAPONOV, I.; FRIML, J.; HEIDSTRA, R.; AIDA, M.; PALME, K.; SCHERES, B. The PIN auxin efflux facilitator network controls growth and patterning in Arabidopsis roots. Nature, Tokyo. v. 433, p.39-44, 2005.

FAUGUEL, C.M.; VEGA, T.A.; NESTARES, G.; ZORZOLI, R.; PICARDI, L.A. Anatomy of normal and hyperhydric sunflower shoots regenerated in vitro. Helia, Serbia, v. 31, p.17-26, 2008.

FERREIRA, D. F. Análises estatísticas por meio do Sisvar para Windows versão 4.0. In: REUNIÃO ANUAL DA REGIÃO BRASILEIRA DA SOCIEDADE INTERNACIONAL DE BIOMETRIA, 45., 2000, São Carlos. Anais...p. 255-258.

FRÁGUAS, C.B.; DORNELLES, C. M. DA V.; LIMA, G. P. P. Benzilaminopurina e ácido naftaleno acético na indução e multiplicação in vitro de gemas de abacaxizeiro da cultivar 'IAC Gomo-de-mel'. Ciência Rural, Santa Maria, v. 39, p. 1682-1687, 2009.
GERLACH, G. Botanische mikrotechnik. Stuttgard: Georg Thieme Verlag, 1969.

HRUBCOVÁA, M.; CVIKROVÁA, M.; EDERA, J.; ZON, J.; MACHÁC` KOVÁA, I. Effect of inhibition of phenylpropanoid biosynthesis on peroxidase and IAA-oxidase activities and auxin content in alfalfa suspension cultures. Plant Physiology and Biochemistry, New Delhi, v. 38, p. 949-956, 2000.

HUANG, S.; DAI, Q.; PENG, S.; CHAVEZ, A.Q.; LOURDES, M.A.; MIRANDA, L.; VISPERAS, R.M.; VERGARA, B.S. Influence of supplemental ultraviolet-B on indoleacetic acid and calmodulin in the leaves of rice (Oryza sativa L.). Plant Growth Regulation, New York, v. 21, p. 59-64, 1997.

JENSEN, W.A. Botanical histochemistry (principles and pratice). San Francisco: W. H. Freeman and Company, 1962.

JOHANSEN, D.A. Plant microtechnique. New York: McGraw Hill Book, 1940.

KUMAR, S.; KASHYAP, M.; SHARMA, D. R. In vitro regeneration and bulblet growth from lily bulbscale explants as affected by retardants, sucrose and irradiance. Biologia Plantarum, Praha, v. 49, p. 629-632, 2005.

LAI, C.C.; LIN, H.M.; NALAWADE, S.M.; FANG, W.; TSAY, H.S. Hyperhydricity in shoot cultures of Scrophularia yoshimurae can be effectively reduced by ventilation of culture vessels. Journal of Plant Physiology, Stuttgart, v. 162, p. 355-361, 2005.

LESHEM, B.; WERKER, E.; SHALEV, D.P. The Effect of cytokinins on vitrification in melon and carnation. Annals of Botany, London, v.62, p. 271276, 1988 .

LIU, Z.H.;HSIAO, I.C.; PAN, Y.W. Effect of naphthaleneacetic acid on endogenous indole3 -acetic acid, peroxidase and auxin oxidase in hypocotyls cuttings of soybean during root formation. Botanical Bulletin of Academia Sinica, Taipei, v. 37, p. 247-253, 1996.

MATOS, A. D.; CABRAL, J.; SOUZA, A. D. S.; FUKUDA, W.; SANTOS FILHO, H. P.; DANTAS, J. Uso da cultura de tecidos no Centro Nacional de Pesquisa de Mandioca e Fruticultura. ABCTP Notícias, Brasília, v. 8, p. 2-5, 1998. 
MURASHIGE, T.; SKOOG, F. A revised medium for rapid growth and bioassays with tabacco tissue culture. Physiologia Plantarum, Rehovot, v.15, p. 473-497, 1962.

O'BRIEN, T.P.; FEDER, N.; MCCULLY, M. E. Polychromatic staining of plant cell walls by toluidine blue. Protoplasma, New York, v.59, p.368373,1964

OLIVEIRA, D. Nova técnica aumenta produção de abacaxi. Banco de notícias da EMBRAPA. 2001. Disponível em: <http://www. cnpmf. embrapa. br/ jornal/index. htm>. Acesso em: 3 abr. 2013.

PASTERNAK, T.; RUDAS, V.; POTTERS, G.; JANSEN, M.A.K. Morphogenic effects of abiotic stress: reorientation of growth in Arabidopsis thaliana seedlings. Environmental and Experimental Botany, Elmsford, v. 53, p. 299-314, 2005.

PIATCZAK, E.; WIELANEK, M.; WYSOKINSKA, A. Liquid culture system for shoot multiplication and secoiridoid production in micropropagated plants of Centaurium erythraea Rafn. Plant Science, Amsterdam, v. 168, p. 431-437, 2005.

SALISBURY, F.B.; ROSS, C.W. Fisiologia vegetal.
México: Grupo Editorial Iberoamérica, 1994.

SANTANA, L.L. de A.; REINHARDT, D.H.; CUNHA, G.A.P. da; CALDAS, R.C.Altas densidades de plantio na cultura do abacaxi cv. Smooth Cayenne, sob condições de sequeiro. Revista Brasileira de Fruticultura, Jaboticabal, v. 23, p. 353-358, 2001.

SINGH, S.K.; SYAMAL, M.M. Anti-auxin enhace Rosa hybrida L. micropropagation. Biologia Plantarum, Praha, v. 43, p. 279-281, 2000.

SUN, O.J.; SWEET, G.B.; WHITEHEAD, D.; BUCHAN, G.D. Physiological responses to water stress and waterlogging in nothofagus species. Tree Physiology, Oxford, v. 15, p. 629-638, 1995.

TOLDI, O.; GYULAI, G.; KISS, J.; TAMÁS, I. A.; BALÁZS, E. Antiauxin enhanced microshoot initiation and plant regeneration from epicotyloriginated thin-layer explants of sugarbeet (Beta vulgaris L.). Plant Cell Reports, Berlin, v. 15, n. 11, p. 851-854, 1996.

TOMA, I.; TOMA, C.; GHIORGHITA, G Histoanatomy and in vitro morphogenesis in Hyssopus officinalis L. (Lamiaceae). Acta Botanica Croatica, Zagreb, v. 63, p. 59-68, 2004. 